\title{
Conflicts in the Caucasus Region and Its Effects on Regional Security Approach
}

\author{
Ahmad Jansiz ${ }^{1} \&$ Mohammad Reza Hojaste ${ }^{1}$ \\ ${ }^{1}$ Department of Political Science, University of Guilan, Rasht, Iran \\ Correspondence: Ahmad Jansiz, Department of Political Science, University of Guilan, Rasht, Iran. Tel: \\ 98-912-384-4835. E-mail: jansiz@guilan.ac.ir
}

\author{
Received: December 12, 2014 Accepted: January 9, 2015 Online Published: February 18, 2015 \\ doi:10.5539/jpl.v8n1p83 \\ URL: http://dx.doi.org/10.5539/jpl.v8n1p83
}

\begin{abstract}
Considering the geopolitical, geo-strategic and geo-economic characteristics of Caucasus region, it has been prone for conflict, tension and competition by regional and trans-regional powers from a long time ago. On one hand, the existence of a mosaic of ethnics and cultures in this region has always been a factor for attracting tribunal, social and political conflicts. The collapse of the Soviet Union, divided Caucasus into two parts of North and South. The states of Azerbaijan, Armenia and Georgia were located in the South Caucasus and the other ones were located within the boundaries of Russia and called North Caucasus. South Caucasian republics made a lot of effort to achieve a new position in the region and regulate their foreign (political) bonds after independence according to their historical background and the emergence of a new political atmosphere in the region and the world. The fire of conflicts and tensions in the South Caucasus, the imbalance in the region, the frustration of some countries during the conflicts in Nagorno-Karabakh, Abkhazia and Ossetia, resulted in a gradual divergence of Russia's Caucasian republics. In this condition, the way was paved for the presence of new players especially the United States of America and NATO. In this paper, the history of the Caucasus crisis and its impact on the security and geopolitical condition of neighboring countries and particularly Iran and the future conditions of the region is analyzed.
\end{abstract}

Keywords: Caucasus, security, geopolitics, Iran, Russia

\section{Introduction}

World in the twentieth century witnessed three major events in its geopolitical structure, conflict World War I, conflict World War II and the collapse of the bipolar system or the end of the Cold War. In each of these events, geopolitical structure of the world has changed and the cast of power, strength relationships and areas of competition and cooperation and the geopolitical landscape of the world has changed. Some governments were removed of the world political map and new states emerged. Basically any kind of political and geopolitical developments in the global and regional power structure can lead to instability as well as changing the geopolitical landscapes. Some instabilities and unrests emerged after establishing a new system of power balance will be replaced gradually with peace and stability. Former geopolitical development is towards the establishing a new structure.

Geopolitical balances have dynamic character and the internal and external variables target the existing balance constantly and lead the processes toward establishing a new balance. Thus, evolution of equations has become a steady current that leads to developing a global geopolitical system. With the collapse of the Soviet Union as one of the poles of the global power structure in the second half of the twentieth century, the global power relations and geopolitical structure was changed. The most important changes are as follows:

1) America as a world power remained without rival and announced a new world order and struggled to control the affairs of the world in the form of a single power structure and led the war against Iraq and the liberation of Kuwait in 1991 and since then we are still experiencing this unrivaled look at global issues.

2) The geographical areas administered or influenced by the Soviet Union in its South and West faced with a power vacuum and competition model. Additionally, instability and conflict was formed within them. Central Asia, Caucasus, Balkans and Eastern Europe are areas that after a period of instability have experienced some forms of stability and relative peace. 
The collapse of the bipolar system led to two waves of regional instability in the world:

a) The first wave was related to early 1990s and influenced the geographical areas of the South and West of the former Soviet such as Central Asia, Caucasus, Balkans and Eastern Europe. This wave began to be controlled and the mentioned areas achieved a relative and fragile calm.

b) The second wave made the Middle East unstable, especially in the early twenty-first century and is still continuing increasingly. This instability is the result of the confrontation between the two main actors, i.e., the trans-regional actor and especially America that is seeking to control this geographic area and the regional players including a collection of some states and nations as well as organized groups that are not necessarily consistent and united with each other and this phenomenon partly reflects what Samuel Huntington calls the "Clash of civilizations of the West and Islam" (Huntington, 1993).

The result of this confrontation and conflict is the development of the crisis in the Middle East and even spread of the competition range and fight to the surrounding area and the development of geopolitical processes in West Asia and Eurasia and Central Asia. This issue of Palestine, Israel, Lebanon, Iraqi crisis, Karabakh crisis and the conflicts in Caucasus especially the South Caucasus, issues and conflicts of Central Asia and tensions and distrusts of the countries of the region towards issue of Afghanistan, Pakistani security crisis, confrontation crisis between Iran and America. The question of legitimacy of governments, spread of fundamentalist beliefs, development of Arabic, Turkish and Iranian gaps defined as term "triangle of gap", insecurity and terror crises are clear examples in this regard. These crises provide the necessary potential to develop instability, insecurity and change.

Conflicting forces in this region have different functions in terms of their interests and often oppose with each other. The Soviet collapse divided Caucasus into two parts. Thus, the states of Azerbaijan, Armenia and Georgia in the South Caucasus and the remaining lands as the North Caucasus were placed within the borders of Russia. North Caucasus region is located in a remote and under developed region and has a strategic importance. This area served as a guard for Russia against the Muslim World and in fact has the role of a buffer zone and defensive line for Russia. Residents of this area have their own customs and are Muslims apart from Ossetians.

Independence of the Caucasus countries and Central Asia and the collapse of the old order, led to geopolitic irregularities in the region and consequently global geopolitics have changed somewhat. These transformations are accompanied with the elements and factors that have made the situation in the region more complex due to coexistence of these republics in the Soviet Union. This situation in the new born independent states is faced with threats which can lead to instability in the region. In fact, the internal situation in the Caucasus countries and their external relations can alter the balance of power in the region. Any change in the relations and balance of power in the region affects the neighboring countries especially Russia, Iran and Turkey, and this limited circle will be widened by joining a number of other countries.

\section{Literature Review}

The book Regions and Powers: The Structure of International Security by Barry Buzan and Ole Waever, from a theoretical point of view, has greately contributed to this article. This book, in spite of being the continual of recent studies in the field of international peace and security, is particularly important from the perspective of regional studies, too.

In their book, Buzan and Waever clearly show the relationship between security processes and the formation of regions. They believe that the end of the Cold War has increased the importance of regional level in international security although this does not mean the supremacy of regional level over domestic or international level in terms of security in all regions.

This book develops the idea that since decolonization, regional patterns of security have become more prominent in international politics and relations. The authors combine an operational theory of regional security with an empirical application across the whole of the international system. The main focus is on the post-Cold War period, but the history of each regional security complex is traced back to its beginnings. By relating the regional dynamics of security to current debates about the global power structure, the authors unfold a distinctive interpretation of post-Cold War international security, avoiding both the extreme oversimplifications of the unipolar view, and the extreme deterritorialisations of many globalist visions of a new world disorder. Their framework brings out the radical diversity of security dynamics in different parts of the world.

Buzan believes that in the CIS, a great power, Russia, is located in the center. The idea of CIS changing into a standard regional security complex, in case of the relative decline of Russian power, is possible. In this region, the security situation is relatively complex: a wierd combination of security regime, the formation of conflicts, 
and efforts for a hegemonic regime (Buzan, 2003).

On the other side, Birthe Hansen, Peter Toft and Anders Wivel in their book Security Strategies and American World Order: Lost Power, examined the security importance of Russia's border regions. In their view, the soft balance of Russia with major powers since the mid-1990s was supported by the regional strategy of this country in borderlands. After the Soviet Union collapsed in 1991, much of Moscow's influence in the border regions was lost. However, in the late 1992, Russia showed its border approach based on saving the influence. These borderlands have long been important due to security, cultural, and economic reasons. These countries played roles in the field of security purposes such as preventing the spread of instability from the South Caucasus to Russia. Moreover, these regions play an important role in the optimal functioning of the Russian air defense system of radar stations. These areas contain the human and material resources necessary for the Russia to achieve superpower status again. Therefore, it is important to understand the strategy of Russia about border regions. In these regions, Russia often uses subtle ways of depending and "Divide and Rule" rather than outright military invasion or full-scale threat (Hansen, Toft \& Wivel, 2009).

\section{Methodology}

This research has been done using descriptive-analytical research method. To explain the purpose of the article properly, the post-Soviet political developments in the Caucasus region were reviewed and their dimensions were analyzed. This research aims to identify the impacts of the regional crisis of Caucasus on security conflicts of the area. Therefore, first, the geopolitical importance of the region, population, cultural, and identical mosaics of region communities, the role of regional and trans-regional players such as international organizations and governments in Caucasus conflicts and security plans of regional and trans-regional players have been investigated; afterwards, the results were reviewed and the future prospective was expressed.

Data collection was conducted using library methods and researchers referred to authentic books, journals, and regional and international media to access the information.

\section{The Spatial Range of the Caucasus and the Political Components of This Geographical Area}

Use of the term Caucasus for the name of this region dates back to the early 19th century. In fact scientists of Academy of Sciences St Petersburg during the Petrus I, era -Russian tsar-applied the name of Caucasus for the first time. Now when we look to the Caucasus region from the perspective of political, geographical, cultural and ethnic boundaries, we face with different definitions of the region of Caucasus each with distinct boundaries.

Geographers divide Caucasus to the Northern and Southern parts. In this division North Caucasus includes autonomous republics such as Adige, Qarachay-Cherkessia, Kabardino-Balkaria, Balkar, North Ossetia, Chechnya, Ingoshia and Dagestan that are located within the borders of Russia. South Caucasus includes Azerbaijan, Armenia and Georgia republics with considering the autonomous republics of Abkhazia, Nagorno-Karabakh, Nakhchivan and South Ossetia. South Caucasus is a so-called artificial term and its real name in the literature of the region is "Beyond-Caucasus". Russians name it «Zakavkay» and British people call it «Trans-Caucasia». Ottomans and Arabs have called it Mavera-e-Caucasus (Demir, 2003: 59).

\subsection{General and Identity Features of Caucasus}

Caucasus is a region between the Black Sea and the Caspian Sea and contains the Caucasus Mountains catchment generally. This region, despite being geographically united, but is various in terms of cultural - social aspects and even historical indicators. Caucasus is considered as the confluence and the border between the Islamic -Eastern Culture with Western- Christian culture (Orthodox). This region has a history of several thousand years of civilization and culture. Its passage and road position has historically made suitable this area to be the place for collision of different cultures and civilizations (Afshordi, 2001: 79). Caucasus is the border between the dominant cultures of the region, i.e., Russian, Turkish and Persian cultures. This area can be a part of the Three Kingdoms of the Ottomans and the Russians in the past and now is known as the border region between the three neighboring countries of Iran, Turkey and Russia. In the end Caucasus is considered as the "mosaic of ethnics". In this geographical area, more than 50 ethnic and linguistic groups of the language families of Turkish -Altaic, Indo- European and Caucasian- Iber live together (Amir Ahmadian, 2004: 320). Also, 36\% of the Caucasian population is Turkish and 56\% of its lands belong to Turks (Illhan, 2005: 205).

\subsection{Geopolitical Characteristics of the Caucasus Region and Its Position in the International System}

Considering the geostrategic and geopolitical situation of Caucasus region, it has always been considered one of the centers of regional and trans-regional attention. Before the collapse of the Soviet Union. The most important factor of geopolitical and geo-economical importance of this region was its role as the main relationship passage of the Soviet through Iran and Black Sea with the outside world as well as its strategic role as a defensive shield 
for the communist world against global capitalism. However, after the collapse of the Soviet Union, considering the geopolitical realities of the region and the surrounding areas including the legal regime of the Caspian Sea, the Caucasus role for exporting the Caspian and Central Asian energy resources to international markets, the transportation and communication situation of Caucasus among the geopolitical fields of Central Asia, Middle East, Black Sea and Anatolia and consequently the continuity and geopolitical interests of Caucasus with the surrounding geopolitical regions, the regional and trans-regional interests in the Caucasus, the ethnic-linguistic and complex interwoven political geography of the region and its cultural affinity with the surrounding areas, geopolitical conflicts in the region, strong repulsive forces and behavioral patterns between the governments in the region in political and economic relations with each other and with the regional and trans-regional governments and accordingly, the geopolitical pattern of the region, Caucasus has found special role in the regional and international geopolitical and geo-economical equations.

Also, the Caucasus is located on the corridor connecting North-South and West-East and is considered the Border crossing of the two great civilizations of Islam and Christianity, and the entrance gate of Great Powers to the Central Asia region and is the only communication road to the world of Turkish countries (Turkey and Turkic states of Central Asia). Moreover, there is also considerable underground resources in this area and its other geopolitical -geo-economical advantages that have attracted the attention of regional and trans-regional powers to this area (Gholizadeh, 2008: 456).

There is no eminent power in Caucasus region in terms of structure and hierarchical system of power and in terms of power structure associated with regional and trans-regional geopolitics. However, one can say that Republic of Azerbaijan is ranked first in the region in terms of the local authority level and Georgia and Armenia are placed in the next ranks.

In other words, Republic of Azerbaijan is the most powerful government of this region and has the strongest army as well. It is worth noting that this country with the helps of the West has formed the most advanced army of Caucasus region. Azerbaijan's proven oil reserves were as many as 7 billion barrels at the end of 2008 that consist about one percent of the world's proven reserves. Moreover, Azerbaijan's proven gas reserves has been 2.1 trillion cubic meters and this country has produced 14.7 billion cubic meters of gas annually; as a result, it has joined to the exporters of gas in the region.

Republic of Azerbaijan has succeeded to reach its GDP from 4.2 billion in 1994 to 3.46 billion dollars in 2008 . At the same time, per capita income has reached from $319 \$$ in 1995 to $5321 \$$ in 2008 (approximately seventeen-fold increase). Azerbaijan's Government consumes 7.22\% of GDP and its annual budget deficit is less than 1\%. Since 2003 the exchange rate of Manat (monetary unit of Azerbaijan) has been strengthened against Dollar and the national currency has been benefiting from stable power. In 2007, in Azerbaijan, about 5 billion $\$$ direct investments have been carried out which is unprecedented in the region (Amir Ahmadian, 2008: 22).

The opening of pipeline, Baku-Tbilisi-Ceyhan and gas pipeline, Baku-Tbilisi-Erzurum has increased the revenues of Azerbaijani government and its double-digit GDP growth in recent years has surprised observers. Investment in oil and energy industry has transformed the face of this country as well as economic, social and eventually political structure of the country. Accordingly, Azerbaijan is going to play role relying on regional and trans-regional allies and powerful structures earned through oil revenues. This is despite the fact that, the armed forces of Azerbaijan are trained and modernized based on European standards. It has been said that, Azerbaijan may join NATO earlier than Georgia and Armenia. Therefore, Baku has become a center for traveling and visiting world leaders and senior officials of the world. In this regard, international conferences, formal meetings, holding festivals and international congresses and other measures of Azerbaijani government play a greater role in the region and the world, and represent that Baku is willing to be internationalized.

Also, choosing Baku as the cultural capital of Islam world in 2009 by UNESCO and ISESCO, show the potentials of Azerbaijan in international important occasions. Thus, the Republic of Azerbaijan not only does not feel any threats but also wants to adopt an independent foreign policy by focusing on economic empowerment and supports of companies that have invested in this country. As a reminder, less country can be found that despite the crisis in the international territorial integrity can take steps towards the development of infrastructures. Azerbaijan has reached a degree of power in all areas (wealth, industry, education, science, culture and the armed forces) that can easily conquer Karabakh front by mobilizing the young and gain its sovereignty in the area again. But the Azerbaijani authorities are well aware of the fact that a bad peace is better than a good war. There is no winner in a war and even the victorious side of the war is lost in fact.

On the other hand, the most important characteristic of the region in the global system is the regional geostrategic function in the area of competition between surrounding powers and trans-regional powers in the 
region. Caucasus region in the field of supplying fossil energy and sending it to the international markets play an important role too. Also, this region acts as the entrance and exit gate of Central Asia in the area of geopolitical competitions of the great powers. In this regard, the South Caucasus is geostrategically important as a corridor connecting Europe to Central Asia and as a bridgehead to control and impose pressure on Iran and also because the energy reserves and the war against terrorism are the main reasons for the presence of the United States in the region. The United States with heavy military operations in Iraq and Afghanistan and after the rotation of Uzbekistan to Russia, attempts for acquisition of the main points of the Caucasus and supporting its global geostrategy.

\subsection{Geopolitical and Security Events in the Region of Caucasus}

South Caucasian republics made many attempts to obtain a new position in the region and regulate their international relationships after independence due to their historical background and the emergence of new political atmosphere in the region and the world.

The most factors affecting the security developments in the Caucasus include:

- Extensive changes in many concepts of international relations especially the West's redefinition of the concepts of security and threats after the end of the Cold War;

- Political and economic turmoil of Russia and its impacts on domestic and international standing and foreign policy of this country, e.g., inactivity and inefficiency of Russia's policy toward Caucasus;

- West-orientation and being affected by the Western models in the South Caucasus Republics, especially Azerbaijan and Georgia;

- Enhancing the role of energy and transport equations in the Caucasus which is also a product of opening political, economical and security atmosphere.

Moreover, these developments and influential factors on one hand lead to a gradual divergence of the Caucasus republics especially the two republics of Georgia and Azerbaijan from Russia and the Commonwealth of Independent States; and on the other hand, has prepared the ground for the presence of new players especially the United States of America and NATO (Faghani, 1998: 20).

Nevertheless, the roots of instability in the Caucasus region dates back to the days before the collapse of the Soviet Union and some experts believe that transformation of the Caucasus accelerated the Soviet Union effectively. In fact the first attempt for separatism happened before the collapse of the Soviets and during the Gorbachev era in the South Caucasus. Additionally, the North Caucasus ethnic conflicts began in 1989 from Abkhazia region. In the same year, South Ossetia separatists called for secession of Georgia and joining to Russia. In 1991, approximately 150 thousand Armenian residents of Nagorno-Karabakh declared autonomy form Azerbaijan Republic that eventually this request led to a bloody war between Azerbaijan and Armenia and this crisis has still remained unsolved after many years. In this region, in addition to the rigorous demands of separatism, sometimes separatist efforts of Taleshes and Lezgis can be observed in Azerbaijan (Amir Ahmadian, 1995: 195).

In the North Caucasus, Chechnya's declaration of independence from Russia in 1991 and its separatism is the most important change that later led to a long war with the Russian central government. Also in November 1992 Russia declared a state of emergency in North Ossetia and Ingushetia due to territorial conflicts and critical situations, and strengthened its military presence in the region significantly. All of these conflicts were the first signs of occurrence of ethnic clashes after the collapse of the Soviets. In fact, the mentioned terms have made the Caucasus region vulnerable in terms of security.

Major threats and challenges arising from the policies of the leaders of the former Soviet Union that the newly-independent states are grappling with today are as follows:

- Drawing artificial boundaries between federal and autonomous republics of the former Soviet Union has been carried out regardless of the reality of racial and ethnic differences in the regions and republics and their records in accordance with national interests and goals of the Soviet leaders. In this regard, ethnic differences have caused a discontinuity at the boundaries of their lands as they were the reasons for the separation of the races. Therefore, if the differences are not contained and controlled, the possibility of further changes in the present borders exists. These changes can cause serious negative consequences for the stability of the region (Jalali, 1993: 118). (For example, Nagorno-Karabakh conflict between Azerbaijan and Armenia in the Caucasus region).

- Weak economy foundations and infrastructures of the newly-independent Republics, that is commonly because of the economic disparities between Russia and other former Soviet republics, has carried out to bind them to 
Russia, and quell any claim of independence.

- Elimination of religion by Soviet communist system and its dissension policy for governing according to centralization policies.

- Cultural matching of different ethnic groups around Russian culture (or through Russian dominance) and depriving individuals identity with slogans such as the plan of "new leading man" (Vaezi, 2002: 55).

That is, while Caucasus has a variety of climates and geographic landscapes and about 50 ethnic groups of three major language families are living in the region (Amir Ahmadian, 1995: 189). In fact, cultural landscapes of the Caucasus are more diverse of its geographical perspectives. Caucasus is the confluence of Islam and Christianity. This condition has led to major conflicts in some cases. Although the three countries located in Caucasus region have their own language and indigenous populations but each of these countries have different minorities. In contrast to the people of the Central Asian region, the majority of its people are Sunni. The number of religions in the Caucasus each related to separate national minorities has made complex the situation of this region more.

Majority of the population of Azerbaijan are followers of the Shiite. The majority of the people of Armenia and Georgia each are connected to a branch of the Eastern Orthodox Church and Armenians and Azerbaijanis reside in Georgia, Russia and other republics too. A significant number of the populations of Nagorno-Karabakh Autonomous Region are also Armenians. In addition, the Nakhchivan Autonomous Republic with a majority of Azerbaijani Turk territory are isolated and surrounded by Iran, Armenia and Turkey.

Autonomous republics of Ajaria and Abkhazia as well as Ossetia Autonomous Region have a substantial minority and separatist forces in Abkhazia and North Ossetia are active. However, the most complicated situation is related to the North Caucasus region that contain shared border of the Russian Federation with the South Caucasus countries. North Caucasus region with more than 19 local and ethnic groups (according to the latest census of the Soviet Union in 1989) and a significant number of people of Russian descent as well as Kazakh minorities, Nogay and some other groups has become one of the most diverse ethnic and linguistic regions of the world. And by considering three main linguistic groups as well as existing religions in the region and also many ethnic groups will have more complex situation too (Vaezi, 2002: 57).

While in the Caucasus, because of the dominance of ethnic attitudes and the Communist beliefs among leaders of these countries and the unwillingness of local governments, civil societies such as political parties and non-governmental organizations have not yet reached proper maturity and growth over the past decade, the civil society organizations of Caucasus are not able to break down ethnic boundaries commonly. Civil society has ethnic functions and its area of expansion does not exceed from the borders of a certain ethnicity or even in some cases a specific geographic region (e.g. Nakhjivanis). These groups of civil institutes not only are not mediation for establishing security and stability, but also in some cases become a factor for the development of conflict and instability (Aydin, 2000: 165).

In fact Caucasus countries are seeking to fill the vacuum created after the collapse of the Soviet Union. So they have involved in a competition to create influential environments and gain maximum benefits from the new position. These transformations are not limited only to the Caucasus and the consequences of these policies can affect the broader region (Vaezi, 2002: 58).

It should be mentioned that Caucasus countries according to their potential are faced with some opportunities for economic development. Choosing poor economic development patterns that do not lead to economic prosperity and improving people's lives can lead to increased instability. Increasing the income of the countries of the region from the sale of natural resources has led to differences in the lives of people and has created migrations caused by economic interests and consequently has transformed ethnic groups polarization and can expose the regional security with some threats.

Given that the economy of these republics is heavily dependent on Moscow and the leaders of newly-independent states did not choose independent economic policies after independence, some economic analysts expressed skepticism about solving the inefficiency of economic structure of Caucasian countries. Gumpel believes that economic problems of these countries depend on a set of economic, cultural, domestic politics and international relations or according to Nikolai Shisilef, these republics need for foreign economic assistances for at least 20 years for ending the poor economic situation (Gumpel, 1994: 40-43).

Also, competition for access to oil and gas resources of the Caspian Sea can also cause tensions. If you spend the revenues of oil for military purchases in order to achieve political objectives of regional competitiveness, the balance of the region is distracted and this will result in instability of the region. The exploitation of economy and specially oil and granting concessions to foreign countries to resolve conflicts in their favor is another factor 
for the competition between regional and trans-regional powers that can cause instability in the region.

\subsection{The Main Conflicts in the Caucasus Region}

Independence of the Caucasus and Central Asian Countries and collapse of the old order caused irregularities in the geopolitics of the region that consequently led to change of global geopolitics of the world. These developments emerged with elements created from the coexistence era of these republics in the Soviet Union territory and have complicated the situation of the region. The situation created within the newly-independent states can lead to instability in the region. In fact, the internal situation of the Caucasus and foreign relations of its states has changed the balance of power in the countries of this region. Obviously, any change in the relationships and balance of power in the region affect initially on the neighboring countries, especially Russia, Iran and Turkey. Then this limited circle becomes more widespread by joining a number of other countries. In fact, the Caucasus countries are seeking to fill the vacuum created by the collapse of the Soviet Union. Therefore, they have exposed themselves to a competition for creating influential environments and gaining maximum benefits from new opportunities. These transformations are not limited only to the Caucasus and the consequences of these policies can affect a broader region (Vaezi, 2002: 58).

Among conflicts in the Caucasus, Karabakh conflict is one of the complex and long-standing regional events that have large dimensions and it's variables are still unclear and ambiguous. So that this crisis has been continuing till now and has converted to an International and Inter-governmental issue and conflict from a domestic subject over the past years. Karabakh conflict has had profound impact on relations between countries in the region and led to strengthening trans-regional forces presence in this area which led to threatening Iran's interests and creating security challenges. It's typical example can be observed in Azerbaijan security pacts with countries opposing the Islamic Republic of Iran and oppositions activities. Karabakh conflict evolved seriously in the late 1980s in the political atmosphere of the Soviets and after the collapse of the Soviet Union in that turbulent era emerged between two recently established states of Azerbaijan and Armenia as a fundamental conflict. Both countries according to the policies adopted in this regard began a bloody and perfect war that a lot of casualties and displaced persons were some of the outcomes of this war for both sides.

Minsk Group from behalf of the Conference on Security and Cooperation in Europe continued dialogue with the parties of the conflict. Despite the made efforts, this autonomous region strengthened its relations with Armenia. Election of leaders of this region as president of Armenia cleared Nagorno-Karabakh ties depth and breadth with this country during the next years (Koolaee, 2009: 196). In this process, the world witnessed extreme decisions in crisis too. So that in December 1989 the Parliament of Armenia-announced Karabakh as part of Armenia (Eastern Europe, Russia and Central Asia, P. 62).

Although, the fight was stopped in 1994, but the efforts of these governments and international and regional organizations, for finding a mutually acceptable political solution to end the crisis have been fruitless so far. The situation of neither war nor peace between the ruling parties is observed and at any moment there exist the possibility of occurring a war between the two sides.

In the aftermath of the conflict between Azerbaijan and Armenia over Nagorno-Karabakh issue, parts of the Azerbaijan country were occupied by Armenia that changed the geographical situation and distracted transportation between Nakhchivan Autonomous Region and Republic of Azerbaijan. Meanwhile, the flood of refugees from Karabakh and other regions to the conflicting countries (Azerbaijan and Armenia) were flooded and created social and economic problems for both sides.

In addition, due to the proximity of the two countries, longstanding relationship between the two countries, and the loss of diplomatic relations and economic relations between the two sides, many negative effects have affected the economic situation and living conditions and consequently the standards of living and general welfare of the citizens of the two countries. The important point is that late problem-solving and the lack of progress, even negligible, in making required preparations and arrangements to end the conflict make searching and finding hidden capacities difficult in this regard. And the main obstacle on this way is mistrust and hostile attitudes of the parties towards each other and strengthening this view of both sides.

\section{Regional and Trans-Regional Security Approaches of Countries in the Caucasus}

The existence of some economic opportunities as well as security threats in this region has caused that the security of the Caucasus to be converted into a warm political debate from the early stages of independence. In fact, energy resources, potentials of regional experiences as well as the spirit of separatism and insecurity in some areas of this field are among the reasons indicating the importance of security discussion of Caucasus. On the other hand, regional and trans-regional powers' attempts to dominate the political and social situation of 
Caucasus as well as seizing the management of energy resources has led to the presence of trans-regional and neighboring countries to provide various security plans to stay in this region.

Iran, Russia, Turkey, Europe, Union countries and America are among the countries that are trying to strengthen their presence in the Caucasus region by offering a variety of security designs. However, it must be acknowledged that none of the above mentioned plans could dominate the security of the system properly for providing the security of the region geopologically. The most important security plans listed about the region are as follows:

\subsection{Security Plan of Azerbaijan Republic}

Among the three South Caucasus countries, the Republic of Azerbaijan is in a very favorable position in terms of wealth and resources. But in terms of security because of the war with Armenia and the loss of large part of its territory as well as problems it has with other ethnic minorities such as Taleshes and Lezgis is in a very difficult situation and because of loneliness it feels in the war against Armenia is trying to attract the trans-regional powers' attention in the Caucasus, to alter the balance of power in its favor.

This country, according to the nature of its foreign policy is more willing to increase the presence of trans-regional powers in order to provide the security of the region. Accordingly, the approach taken by Baku in order to secure the region is approach of $3+2+2$ that Figure 3 represents the three countries in the Caucasus region, Digit 2 indicates the presence of two regional countries i.e. Turkey and Russia and the last digit represents America and Europe Union as two trans-regional powers. In facing with the presence of Iran as a neighboring country that according to its particular geopolitical situation plays a more influential role in regional security balance, this country is talking and interacting with countries opposing with Iran and has extensive military and security cooperation with Israel to ignore influence and power of Iran in this region. On the other hand, this country with accepting some of the members of the MKO from Iraq's Camp Ashraf and harboring terrorists for training and executing terrorist operations in Iran intends to tighten security circle to Iran and thereby threaten the interests of Iran.

\subsection{Armenia's Security Plan}

Armenia's security doctrine is similar to that of designed by the Organization for Security and Cooperation in Europe for Caucasus region. This security approach known to $3+3+2$ Plan, consists of three countries of the Caucasus region in addition to Iran, Russia, Turkey, plus two trans-regional powers i.e. America and the Union of Europe. Among the three countries of South Caucasus, Armenia Country, given the dire geopolitical situation it is facing with, and the impasse caused by the blockade of Turkey and Azerbaijan, relies on Iran in its policies as a way out of the deadlock and a reliable support in the region and has made several security and economic alliances with Iran since the beginning of independence and despite the insistence of Israel for having an Embassy to this country has refused to accept the request of opening an Embassy to Armenia because of the special considerations as well as special and extensive relationships with Iran. It seems that due to the opening of a new chapter in relations between Armenia and Turkey, geopolitical pressures arising from the impasse over Armenia in the region to be removed and Iran's geopolitical value as the only route linking Armenia to international waters to be challenged and damaged for this country by opening the borders of Turkey.

\subsection{Georgia's Security Plan}

With the collapse of the Soviet Union and the independence of the countries of Azerbaijan, Georgia and Armenia in the Caucasus, five autonomous regions came into being in this part because of the legacy of the communist government policies and political boundaries incongruent with ethnic and racial boundaries in the sub-national level. Existence of autonomous units of Ajaria, Abkhazia, South Ossetia, Nakhchivan, Nagorno-Karabakh in the Caucasus region has been the origin of many political and security developments during the past two decades. Particularly given to bloody civil wars in Georgia over two regions of Abkhazia and South Ossetia which led to the Russian military intervention, Caucasus republics have faced many challenges after independence for forming state-nation.

In the meantime, Russian Federation has been trying to revive its past influence on the region that know it a part of its close exterior area. The traditional relations of the region, with occurrence of Color Revolution known as the Rose Revolution in Georgia in 2003 and taking-power of the West-orientation authorities and anti-Russian regime in this country entered into a new phase and led to a further gap in the area. So that given to differences between Armenia and Azerbaijan, the situation in the Caucasus has become more complex. West-orientation policies of the new leaders in Tbilisi, for establishing a broader relationship with the Euro - Atlantic institutions, including Europe and NATO, exacerbated the conflict between the policies of the West, with the goals and 
interests of regional actors such as Russian Federation in the South Caucasus fragile region. This trend of contrast with Saakashvili's government action in restoring the sovereignty of Georgia's central government over two regions of Abkhazia and South Ossetia, and Russia's more widespread military response in August 2008, reached its climax. That is, some experts with pessimism talked about a new cold war between Russia and the West.

But unlike these expectations, evolution of the Caucasus region continued differently. Change of government in the United States and establishment of the Democrats led by Barack Obama caused Washington to adopt different policy to what's happening in international revolutions especially in relations with the Russian Federation. Moscow also adopted more flexible policies towards developments in the Caucasus region. Also, the establishment of diplomatic relations between Turkey and Armenia, resuming Azerbaijan and Armenia's talks over the separatist region of Nagorno-Karabakh, Georgia's internal problems parallel to holding Zhou negotiations to resolve the separatist crisis in this country are among the most important events of the year developments since 2008 that have affected the Caucasus region. Accordingly, Georgia, similar to Republic of Azerbaijan, has tied its security with regional and trans-regional powers because of the geopolitical situation and the existence of various ethnics. Even now, despite the geopolitical crisis in this country ("South Ossetia" and "Abkhazia" Separatism and the invasion of Russia to these territories under the pretext of defending the breakaway regions) and dissatisfaction dominated on Georgia's society toward the pro-West government of Saakashvili, tendency to the West is followed on political and security issues as a consolidated and institutionalized current by the authorities of this country.

\subsection{Turkish Security Plan}

Turkey has tried to increase its position and role in the region in terms of its foreign policy principles by providing a pattern parallel to removal of fundamental role of the two countries of the region, i.e. Iran and Russia. The model considered by Turkey has proposed, i.e., $3+1+2$, includes three countries of the Caucasus region along with Turkey as a regional power and America and union Europe are considered as members establishing the safety of Caucasus. In this regard Turkey despite the red lines it has in its government with Armenia over the disputed issues has taken some steps for thawing relations between the two countries and achieving Crescent Turkic States of Central Asia and the expanding influence and implementing new - Ottoman policies of Turkish foreign policy. This long skip of Turkey to play role in the region, limits and challenges the interests of two significant powers in the region (Iran and Russia).

\subsection{Russian Security Plan}

Moscow despite the fact that is concerned to the role of Iran in regional developments, but strives to not only does reduce the presence of Iran in the region, but also ignores the role of America, Europe and even Turkey because of the security concerns and the hidden and clear dependencies of newly independent republics to Russia. Moscow is trying to relying on its power, Moscow is trying to play a unique role in the security of the Caucasus region. In the Russian plan, regardless of the impact of regional and trans-regional countries, only the presence of three countries in the Caucasus and Russia has been mentioned. In fact, Russia knows traditionally Caucasus as its security privacy and its backyard and has no desire to the presence of another power such as Iran or America in this region.

\subsection{The Security Plan of Europe Union}

Caucasus countries in terms of having energy resources are important for the Europe Union. In terms of security, Europe Union does not want these countries to have destabilization potential to Europe. In this plan developed by the Organization for Security and Cooperation in Europe. The role of the three countries of the Caucasus region in addition to the three neighbors, i.e., Iran, Turkey and Russia, along with America and Europe Union is stressed (Afshordi, 2001: 331).

The Organization for Security and Cooperation in Europe's plan includes the following terms: Adopting interim status for Nagorno-Karabakh, pending the determination of the legal regime in this area to the future, ensuring the minimum security and self-controlling of lands in the composition of the former province of Nagorno-Karabakh to the framework of the interim regime and the return of the occupied territories surrounding Nagorno-Karabakh to Azerbaijan. Furthermore, creating a link corridor between Nagorno-Karabakh and Armenia from the Lachin region, the return of refugees and the displaced people to their homes, and the participation of peace keepers in the conflict settlement considering the impossibility of guaranteeing the peace without the participation of the forces are among other terms in this regard. 


\subsection{Iran's Security Plan}

Caucasian ethnic conflicts in Nagorno-Karabakh, Abkhazia and South Ossetia indicate the presence of instability factors in the region. In fact ethnic conflicts have led to destroying many of the economic and industrial structures, growth and spread of organized crimes, and above all, the political instability in the region. On the other hand, these conflicts will promote ethnic nationalism in the form of an ideology in the region constantly. Currently, conflicts such as contrast between Azerbaijan and Armenia over Nagorno-Karabakh region, the conflict between the central government of the Georgian and breakaway regions of Abkhazia and South Ossetia still remain unresolved. Although the legacy left by the Soviet Union and the weakness of the central government and foreign interventions are the causes of many of these tensions and their continuation, other factors such as lack of civic consciousness, growth of ethnic feelings among the minorities, and trying to maintain dominance, reviewing history to explore ethnic achievements and finally political extremism have played role in this regard. In addition, other factors also contributed to exacerbation of ethnic tensions in the Caucasus including the salience of ethnic identity in the Caucasus region compared to other regions of the former Soviet Union. Insistence on maintaining the local language, and its diversity in the Caucasus in contrast to the Russian language and lack of moving ethnic groups within the region can be noted.

Iran within its security perspective on the basis of tension-removing has made widespread efforts to engage in providing the regional peace and stability in opposition to any foreign influence in peripheral areas. Undoubtedly geopolitical characteristics, ethnic assimilation and political and economic power have increased Iran's influence to establish stability and security in the region. Within a security perspective, Iran believes that any attempt to militarize the region, building military blocks, and the preparing other involved actors can not provide lasting security. The security of the region should be established by the countries of the region.

According to Islamic Republic of Iran, a principal and sure formula which is a base for common and mutual understanding of all countries in the region can ensure any security arrangements excluding one or more countries not only is not perfect, but also leads that excluded countries to be able to emerge as a source of insecurity in the region. Hence, the model that Islamic Republic of Iran has provided for the local and regional crisis management and establishing security and stability in the South Caucasus countries is called Formula 3+3, includes the three Caucasus countries of Armenia, Azerbaijan and Georgia, and three neighboring powers, i.e., Russia, Turkey and Iran. However, Iran is not opposed to the presence of other countries after the creation of security arrangements if they are not destructive to the peace and stability in the region, but has adopted security-making approach based on collaboration with other regional actors to resolve challenges and issues of security in order to reduce security threats caused by environmental surroundings and to help improve regional security. In this context, contributing to formation of strong and capable states for managing internal conflicts and instabilities is essential. Secondly, increased collaboration between local governments and transparency and exchange of information can lead to improved security in the region.

In this context, restricting the influence and power of trans-regional powers in security system of the region to help create the native security system in Iran's approach is important. But this does not mean ignoring international capabilities and facilities in order to promote regional security and reducing challenges and instabilities. But we can utilize all international potentials in the form of international organizations in order to reduce volatility and stabilizing and strengthening the political and economic structures as factors underlying security-making in the region.

\section{Conclusion}

The Caucasus is known as a mountainous, historical and a crossroad between East and West, North and South, and Europe and Asia. During the cold war the Caucasus region was considered a remote and neglected area. But after the collapse of the Soviet Union, the geopolitical face of this area changed completely. Now this region due to its unique political, economic, military, social, cultural aspect is witnessing the political economical, military, social and environmental instability. After the collapse of the Soviet Union, regional wars, ethnic conflicts security challenges, population displacement and ethnic cleansing has been widely performed in the Caucasus. Hence examining the issue of security in the Caucasus appears to be very important.

This region has become the competition center between America and European countries, Russia and China for political and economic influence because of having rich oil and mineral and economic reserves and geopolitical importance. In recent years, regional and trans-regional actors and alienating from the Caucasus each one according to its interests have proposed a different security model for the region that it has added to the complexity of the security issue in the Caucasus.

Caucasus region despite consisting of more than 50 ethnic groups as a dense and heterogeneous area in terms of 
ethnic and religious factors benefits from great potential to create ethnic and identity conflicts in the region. Some conflicts are now ongoing in the form of political and military conflicts and many others have the potential to occur. Karabakh conflict is one of the biggest crises in the region and has a long history as well. And effective steps to resolve this crisis and build a lasting peace are not taken yet. Although the OSCE Minsk Group Europe consisting of three countries of the United States of America, France and Russia are mediating on the issue of peaceful resolution of Karabakh conflict, because of the lack of resolution of the Karabakh conflict, the Caucasus region condition is still critical. Europeans believe that without the absence of security in the Caucasus and Asia Minor, providing Europe security can not be possible. Crises in the North Caucasus can endanger a quiet and safe energy pass from the Caucasus to Western countries. In fact, the risk of social unrest and political instability threatens all regional and trans-regional actors of this geography. The prevailing insecurity in the region slows the speed of development in the countries of the region and will lead to new crises. It appears that Caucasus region needs more serious and effective efforts of regional and international actors and organizations to ensure lasting peace and security.

\section{References}

Afshordi, M. H. (2001). The geopolitics of the Caucasus and policies of the Islamic Republic of Iran. Tehran: The Great War Era.

Aidin, M. (2000). The roots of internal instability in Central Asia and the Caucasus. Caucasus and Central Asian Studies Journal, (36), 159-172.

Amir Ahmadian, B. (1995). Security threats in the Caucasus. Caucasus and Central Asian Studies, (13), 185-198.

Amir Ahmadian, B. (2004). Republic of Azerbaijan-Iran relations. Tehran: Political and International Studies.

Buzan, B., \& Waever, O. (2003). Regions and Powers: The Structure of International Security. Cambridge University Press. http://dx.doi.org/10.1017/CBO9780511491252

Demir, A. F. (2003). Türk Dış Politikası Perspektifinden Güney Kafkasya. İstanbul: Bağlam Yayınları.

Faghani, H. (1998). NATO expansion to the East: Checking the position of Georgia. Caucasus and Central Asian Studies Journal, (26), 18-28.

Gholizadeh, A. V. (2008). The research project: The status and economic advantages of Iran for Commonwealth of Independent States. Aras Free Economic Trade Zone.

Green, J. R. (2008). Eastern Europe, Russia and Central Asia (8th ed.). London: Routledge.

Gumpel, W. (1994). Economic and Political Development in the Central Asia Turkish Republics. Eurasian Studies, 1(2).

Hansen, B., Toft, P., \& Wivel, A. (2009). Security Strategies and American World Order: Lost Power, Taylor \& Francis.

Huntington, S. P. (1993). The Clash of Civilizations. Foreign Affairs, 72(3), 22-50. http://dx.doi.org/10.2307/20045621

Huntington, S. P. (1999, March-April). The Lonely Superpower. Foreign Affairs, 78, 35-49. http://dx.doi.org/10.2307/20049207

İlhan, S. (2005). Bir Millet Uyanıyor 2 (Türklerin Jeopolitiği ve Avrasyacılık), Ankara: Bilgi Yayınevi.

Jalali, M. R. (1993). The Caucasus and Central Asia: Entering the scene and composition of geo-strategic space. Caucasus and Central Asian Studies Journal, (6), 115-124.

Khorasan Newspaper. (2012/05/08), No. 18110, Israel's plan to settle MKO in Republic of Azerbaijan.

Koolaee, E. (2009). Politics and Government in in Central Eurasia. Tehran: Samt Publications.

Vaezi, M. (2002). Instability factors in the Caucasus and security approaches. Caucasus and Central Asian Studies Journal, (44).

\section{Copyrights}

Copyright for this article is retained by the author(s), with first publication rights granted to the journal.

This is an open-access article distributed under the terms and conditions of the Creative Commons Attribution license (http://creativecommons.org/licenses/by/3.0/). 